УДК 811.111'42

ББК 81

DOI: https://doi.org/10.17308/lic.2020.3/2936

\title{
ВЫРАЖЕНИЕ БЛАГОДАРНОСТИ В ДЕЛОВОМ ДИСКУРСЕ (НА ПРИМЕРЕ АНГЛОЯЗЫЧНЫХ ЭЛЕКТРОННЫХ ПИСЕМ)
}

\author{
Л. А. Завьялова
}

Воронежский государственный университет

\section{EXPRESSING GRATITUDE IN THE EMAIL-BASED BUSINESS COMMUNICATION}

\author{
L. A. Zavialova \\ Voronezh State University
}

\begin{abstract}
Аннотация: в статье представлен качественно новый анализ цеепочек электронной деловой переписки, участниками которой являются носители английского языка (британский вариант) и инофоны. Автором подчеркивается, что бытующие на сегодняшний день подходы к анализу эпизодов электронного общения в русле функциональной стилистики или корпусных исследований не позволяют установить весь диапазон коммуникативных смыслов, транслируемых участниками общения, и раскрыть дискурсивные механизмы поддержания кооперативного взаимодействия на протяженных, с точки зрения временных рамок и количества пересылаемых сообщений, и многоголосных, т. е. объединяющих более двух партнеров, участках общения. Расширение дискурсивного контекста и рассмотрение связанных единой электронной веткой эпизодов электронной корреспонденции с позиций дискурсивного анализа позволяет автору выделить три типа выражения благодарности и отметить стратегическое значение различного рода проявления признательности для поддержания гармонии межличностных отношений (rapport) в ситуачиях межкультурного общения. В работе используются примеры из аутентичного корпуса электронной деловой переписки для иллюстрации моделей реализации дискурсивного события выражения благодарности, относимого к эмфатическому типу взаимодействия. Такюе на примерах фактического речевого материала обоснуется обращение участников компьютерно-опосредованного общения к особой стратегии выражения благодарности. Наконеи, приводятся случаи, когда благодарение преследует фатические иели, достижение которых является не менее важным для поддержания бесконфликтного общения. $B$ заключение высказывается мнение о наиболее перспективной методологии изучения электронных писем, позволяющей установить паттерны коммуникативного взаимодействия в электронной среде и наиболее верно интерпретировать смысль, транслируемые интерактантами - носителями и неносителями английского языка.
\end{abstract}

Ключевые слова: электронное письмо, дискурсивное событие, речевой акт, благодарность, межкультурная коммуникация.

\begin{abstract}
: the paper gives a brief analysis of different expressions of gratitude in email exchanges between native (British English) and nonnative speakers of English. It argues that conventional approaches to view this type of communication from the grounds of format letters fail to fully define communicative meanings conveyed by the speakers in order to maintain interpersonal rapport. Drawing on the wide discursive context and contextual use three types of thanking are identified. The paper proves that the speakers are able to fulfill specific rapport management goals by expressing one of these types of gratitude. It is argued that in order to determine discursive patterns of computer-based email communication and understand the exact meanings communicated by the speakers, the discourse approach should be adopted.
\end{abstract}

Key words: email, speech event, speech act, gratitude, intercultural communication.

(C) Завьялова Л. А., 2020

Контент доступен под лицензией Creative Commons Attribution 4.0 License.

The content is available under Creative Commons Attribution 4.0 License. 


\section{Введение}

Несмотря на признание лингвистами неадекватности переноса стратегий написания традиционных форматных писем на электронные сообщения, прежде всего в силу того, что компьютерно-опосредованная среда воспринимается участниками общения как платформа для поддержания диалогического общения на протяжении времени [1, p. 254; 2, p. 29], работы по данной тематике продолжают носить узкий характер, фокусируясь на стилистических особенностях текста писем или количественном анализе отдельных лексем, с целью объяснить устно-письменный характер электронной коммуникации [3; 4]. Предпринимаемые попытки рассмотреть электронные письма с дискурсивных позиций не всегда раскрывают картину реального взаимодействия в связи с тем, что материал для анализа был получен в ходе постановочных экспериментов, в рамках которых участников просят ответить на заранее составленное инициативное письмо, ограничивая тем самым интеракцию двумя коммуникативными шагами. Подобные рестриктивные шаги не позволяют понять, каким образом будет изменяться дискурсивное поведение интерактантов на больших отрезках в зависимости от развивающихся между ними отношений [5].

Принимая во внимание значимость определения механизмов, позволяющих двум и более коммуникантам поддерживать бесконфликтное общение в обменах электронными письмами, не ограничивающихся инициативным и реактивным эпизодами, в настоящей статье нами рассматриваются типы выражаемой участниками общения благодарности в цепочках связанных эпизодов электронного взаимодействия и определяется их стратегическое назначение.

Следует отметить, что в сознании говорящих имеется когнитивный сценарий благодарения, в котором, среди прочего, содержатся знания, прививаемые каждому с малых лет, относительно того, что добрый поступок должен быть оценен «волшебным словом» [6 p. 57; 7, с. 7]. Подобное поведение в современной парадигме изучения лингвистической вежливости получило определение благоразумного или надлежащего [8] ${ }^{1}$.

Согласно довлеющей в дискурсе теории речевых актов, благодарность представляет собой экспрессивный речевой акт, иллокутивная цель которого «выразить психологическое состояние, задаваемое условием искренности относительно положения вещуей, определенного в рамках пропозиционального содер-

${ }^{1}$ В статье рассматриваются случаи благодарности, входящие в поле лингвистической вежливости; подробнее про категорию лингвистической невежливости см.: Быстрых A. B. Невежливая вежливость : к вопросу об ингерентно вежливых формах // Вестник Воронеж. гос. ун-та. Сер.: Лингвистика и межкультурная коммуникация. 2017. № 4. С. 65-70. жания» [9, с. 183]. Для успешной реализации благодарности необходимо, чтобы речевой акт удовлетворял следующим условиям успешности: 1) действие, совершенное говорящим по отношению к собеседнику (условие пропозиционального содержания); 2) совершенное действие является бенефактивным для собеседника и признается им таковым (подготовительное условие); 3) говорящий испытывает благодарность или признание за совершенное относительно него действие (условие искренности); 4) выбранный способ выражения благодарности является приемлемым (существенное условие) [10, р. 67].

Однако, как отмечает Дж. Лич (замечание, справедливость которого мы подкрепим примерами из нашего корпуса далее), британской лингвокультуре свойственна преждевременная благодарность за действие, которое, будучи еще не совершенным собеседником, уже прогнозируется адресантом как выполненное, а результат как удовлетворяющий его ожиданиям [11, p. 198]. Полагаем, что подобная культурная специфика позволяет расширить иллокутивные цели речевого акта благодарности и свести их не только к выражению положительного эмоционального состояния, вызванного определенным поступком собеседника, но и к предвосхищению конфликтов, спровоцированных возможным отказом удовлетворить адресованную просьбу. Более подходящей в таком случае будет определение иллокутивной функции РА благодарности как компанейской, когда иллокутивная цель говорящего совпадает с его социальной целью, обусловленной необходимостью поддерживать гармоничные отношения с окружающими [12, p. 104-105].

В зависимости от типа объекта благодарности, подтолкнувшего говорящего включить рассматриваемый речевой акт как коммуникативно релевантный для его обращения к собеседнику, и отношений между участниками общения предпочтение будет отдаваться различным средствам выражения и стратегиям благодарения. Принимая во внимание объект-стимул, речевые акты благодарности возможно группировать по следующим категориям. Так, первую составляет благодарность ожидаемая или фактическая. Во вторую категорию входит благодарность, вызванная материальными вещами или нематериальными благами, например, комплиментами. Речевые акты благодарности также объединяются вокруг некоего осуществленного в отношении говорящего действия в ответ на просьбу, или действия, инициатором которого выступил собеседник. Отдельную группу составляет благодарность за поступки, вызвавшие у говорящего чувство глубокого морального долга, или, напротив, не имплицирующие никакие обязательства [13, p. 74-75].

Инициальное высказывание благодарности за определенные положительные поступки по отноше- 
нию к реципиенту влечет за собой ответные коммуникативные действия с его стороны, которые, по словам Р. Лакофф, позволяют подтвердить наличие между сторонами определенных отношений и укрепить их [14, р. 298].

\section{Материалы и методы исследования}

Материалом для исследования послужил аутентичный корпус деловой электронной корреспонденции в предметной области «Международное научно-образовательное сотрудничество». Данный корпус составляют цепочки электронных писем, написанные носителями английского языка (британский вариант) и представителями русской, испанской, итальянской, немецкой, французской, греческой лингвокультур, для которых английский является языком-посредником в осуществлении совместной профессиональной деятельности. Каждая отдельная цепочка выступает в качестве диалога между двумя участниками или полилога, когда для решения определенного вопроса требуется участие и осведомленность о действиях/ замечаниях/рекомендациях, эксплицированных в рамках определенной интерактивной цепочки, всеми заинтересованными сторонами. Следует заметить, что количество участников не всегда является стабильным и может расширяться или сужаться в зависимости от серьезности решаемых проблем. Так, например, для подачи совместного научного проекта в Британский совет одна электронная ветка деловой корреспонденции объединила в себе четырех ученых. В рамках каждой из проанализированных нами 101 интерактивной цепочки общим объемом 702 электронных письма реализуется определенное дискурсивное событие, определяемое нами по титульному речевому акту инициативного эпизода общения. Выделенные во всей совокупности электронных писем дискурсивные события составили: ДС выражения благодарности, ДС просьбы, ДС информирования, ДС приглашения.

\section{Результаты исследования}

Обращаясь непосредственно к благодарению, нами было выявлено три типа выражения признательности. Первый представлен ДС выражсения благодарности, где речевой акт благодарности является центральным и реализует коммуникативную цель адресанта, а именно выразить признательность за что-то «хорошее», что было выполнено для него собеседником. Второй тип - особая стратегия благодарения, направленная на поддержание гармонии межличностных отношений (rapport) в ДС просьбы и информирования. Благодарность здесь выступает в качестве реакции на уже исполненное адресатом бенефактивное действие или в виде антиципации адресантом удовлетворения его просьбы партнером по электронному общению. Наконец, участники интеракции описываемого типа прибегают к фатическому благодарению, являющемуся конвенциональным способом установления и размыкания контакта в электронных письмах. Перейдем далее к иллюстрации обозначенных типов благодарности примерами из корпуса.

\section{Дискурсивное событие Выражения благодарности}

Основу дискурсивного события выражения благодарности составляет речевой акт Благодарности и реактивные речевые акты, к которым относятся ответная благодарность и просьба. Анализ корпуса электронной корреспонденции показал, что речевые акты благодарности, рассматриваемые нами в рамках ДС события выражения благодарности, относятся к эмфатическому типу в связи с тем, что благодарность является мотивированной: для адресанта крайне важно выразить собственное положительное эмоциональное состояние по поводу совершенного по отношению к нему и имеющего в его глазах определенный вес действия. Подобными действиями-стимулами в нашем корпусе являются оказанное во время мероприятия гостеприимство, продуктивная встреча, радушие партнера. Ключевым в таком случае, как для центрального, так и поддерживающего речевых актов становится исполнение Условия Искренности [15, с. 63].

Как правило, интерактивная модель дискурсивного события благодарения раскрывается в цепочке электронного обмена в два коммуникативных хода:

[Действие-стимул]

ДХ выражения благодарности (инициативный)

ДХ выражения ответной благодарности (реактивный).

Однако, принимая во внимание гибридный характер электронной переписки, когда одно письмо может включать несколько информационных блоков, каждый из которых преследует специфичную цель, модель реализации рассматриваемого дискурсивного события становится более вариативной:

[Действие-стимул 1]

ДХ выражения благодарности (инициативный)

ДХ выражения ответной благодарности + ДХ Просьбы (реактивный) $+$

ДХ удовлетворение просьбы $+$ [Действие-стимул 2] ДХ выражения благодарности 
Полагаем, что включение дополнительного хода в виде реквестива является оправданным в связи с тем, что адресант уже был расположен к собеседнику благодаря ранее выраженной положительной оценке его действий.

В качестве примера реализации дискурсивного события благодарности, соответствующего интерактивной модели первого типа, приведем цепочку интеракций между сотрудником международного отдела российского университета и носителем английского языка (британский вариант), принимавшего участие в торжественных мероприятиях по случаю юбилея вуза. Оставшись крайне впечатленным визитом и проделанной со стороны коллег работой для успешной организации празднований, британский участник выражает свою признательность (1). Описывая положительные эмоции, полученные им во время пребывания, (2), иностранный гость усиливает тем самым иллокутивную силу речевого акта благодарности и позволяет собеседнику рассматривать его как искренний. Увериться в правдивости слов коллеги российской стороне позволяет также повторное спасибо, употребляемое уже без отсылки на конкретные объекты-стимулы (3).

Заметим, что благодарность предваряется речевым актом извинения (4), который в силу аргументирования адресантом своего проступка (5), рассматривается нами как искренний. Вступление подобного рода свидетельствует о том, что, несмотря на отсутствие кодифицированных временных норм отправления электронного письма с целью поблагодарить за что-то, участник общения полагает, что промежуток практически в месяц является неприемлемым и может потенциально нанести угрозу кооперативным взаимоотношениям. Подкрепление благодарности извинением позволяет избежать нарушения гармонии взаимодействия.

Заметим, что высказывание «I hope to see you again in the future» в блоке прощания не будет провоцировать собеседника к незамедлительному поиску площадок для развития и укрепления сотрудничества, а будет являться конвенциональным способом поддержания канала коммуникации в рабочем состоянии (cp. We could have dinner together one day. - Пример наш. - Л. 3.).

Dear (имя адресата),

Please accept my apologies for this late note of thanks. (4)

I have just returned to London from 3 weeks in Russia, the crowning highlight of which was the University Centenary. (5)

I would like to express my sincere gratitude to you and all of your colleagues for the invitation, as well as for the hospitality, assistance and friendship afforded to all the UK alumni during this visit. (1)

I thoroughlv enjoved the events and was so pleased that I was able to attend. (2)

Many thanks again for all that you and your colleagues did for us (3) and I hope to see you again in the future.

With thanks and warm regards,

(имя адресанта)

В ответном электронном письме представитель русской лингвокультуры также выражает радостные чувства относительно встречи и проведенного времени (1). Участник общения вслед за коллегой оставляет открытой возможность дальнейшего сотрудничества без указания на какие-либо определенные действия, каким образом совместная деятельность будет отлажена (2). Искренность благодарности подкрепляется в данном эпизоде коммуникации интенсификатором «very much» во вступлении и эмотивным определением «heartfelt»в блоке подписи (3):

Dear (имя адресата),

Thank you very much for your letter. (3) It was great pleasure to meet you. I am glad to hear that you enjoyed the visit as much as we all did (1).

We would very much like to see you again. (2)

With kind regards and heartfelt thanks, (3)

(имя адресанта) 
В качестве примера реализации второй интерактивной модели ДС выражения благодарности рассмотрим реактивное электронное сообщение (цепочка объемом 6 электронных писем) профессора немецкого университета его коллеге из российского вуза.

Получив от носителя русского языка благодарность за проделанную работу и фотографии, сделанные во время выступления, представитель немецкой лингвокультуры в ответ высоко отзывается о прошедшей встрече и проведенном вместе с коллегой времени (1), усиливая иллокутивную силу благодарности комплиментами (2). Расположив таким образом к себе собеседника, представитель немецкой лингвокультуры просит его содействовать в организации ряда встреч. Отметим, что просьба выражается прямыми конвенциональными способами, с одной стороны, с помощью вопроса-побуждения с модальным глаголом в форме индикатива (3), а с другой - через хеджированный перформатив (4).

Следует заметить, что благодарность, высказанная немецким профессором в части прощания (5), также будет являться эмфатическим речевым актом и служить не только лишь для размыкания контакта, а для поддержания гармоничных взаимоотношений (rapport), для которых, помимо транзакциональной цели, т. е. передачи релевантной для деловых целей информации, важным является поддержание интеракциональности - сохранения и укрепления дружеских связей [16]. Как видим, в данном высказывании благодарность сопровождается озабоченностью адресата относительно удовлетворенности коллегой своей деятельностью, что представляет собой аллопракт конвенционального фатического речевого акта прощания «Take care». Заинтересованность в благополучии партнера усиливается также экскламативом.

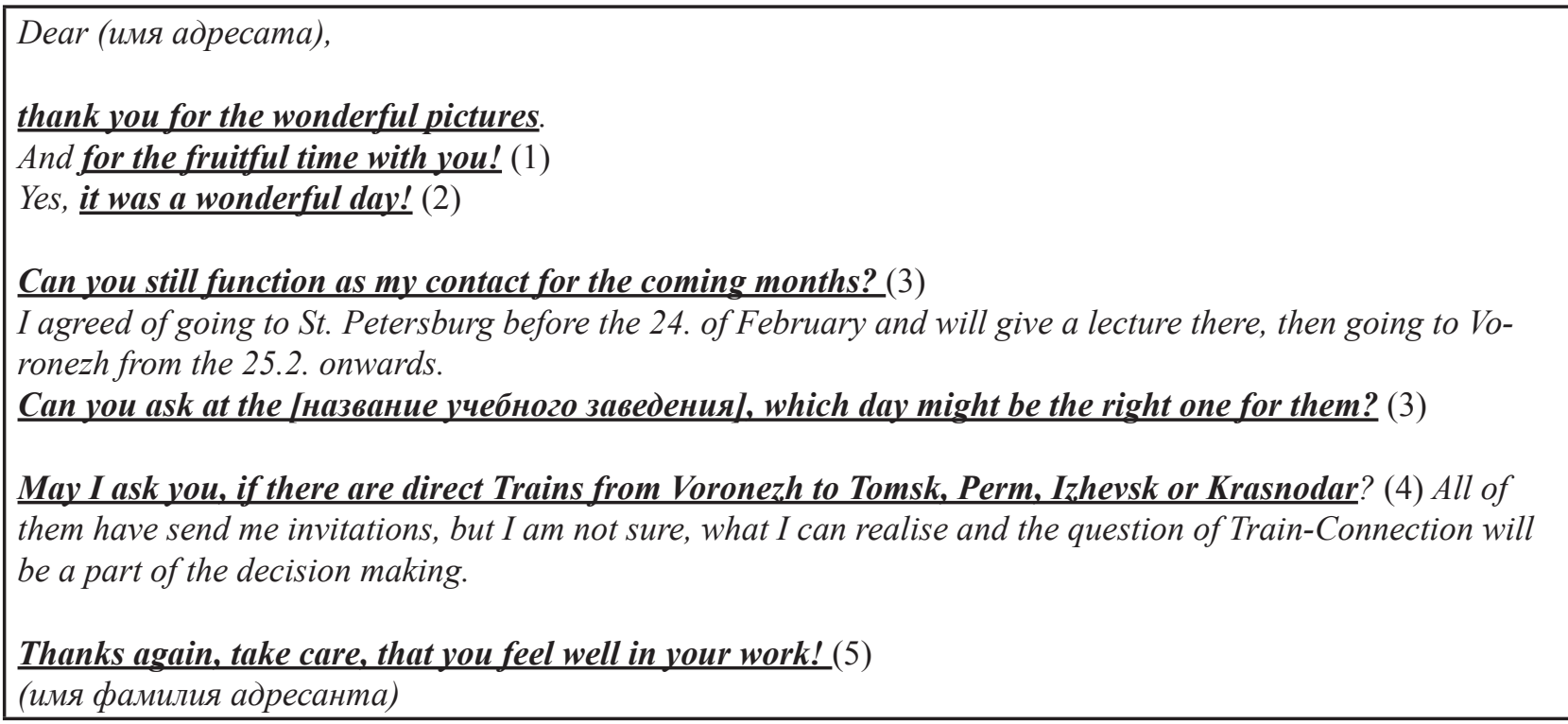

В связи с тем, что в ответном электронном сообщении просьба коллеги удовлетворяется, мы можем говорить о том, что считающийся ингерентно ликоугрожающим реквестивный речевой акт [17, p. 66] не воспринимается адресатом как таковой благодаря заранее созданной немецким профессором коммуникативной подушке в виде благодарности.

\section{Коммуникативная стратегия благодарения}

Как было указано ранее, благодарность может служить определенной стратегией в электронных сообщениях, входящих в отличные от благодарения дискурсивные события. Заметим, что под стратегией мы понимаем «потенцииально возможные интерактивные способы осуществления коммуникативно значимых действий в дискурсе и языковые способы их выражения» [18, с. 101].
Так, стратегия благодарения используется в цепочках деловой переписки, составляющих ДС Просьбы. В качестве примера приведем реактивное письмо профессора российского вуза к британской коллеге по случаю организации академического визита студентов. Данное электронное письмо входит в ветку общим объемом 23 эпизода, причем участниками общения являются одновременно 5 человек, которые, выполняя разные функции на протяжении долгого времени (переписка длится 10 месяцев), должны быть в курсе деятельности своих коллег и в случае необходимости иметь возможность прояснить принятые на более ранних этапах коммуникации решения.

Получив от сотрудника британского вуза, в поле ведения которого входит организация проживания студентов и финансовые аспекты реализуемой программы академических обменов, подтверждение 
порядка поселения, прибытия и отбытия обучающихся, представитель российской стороны выражает благодарность за проделанную работу и помощь в организации визита (1). Поддерживая свою при- знательность комплиментом, дающим положительную оценку деятельности адресата, участник общения тем самым усиливает искренность своих слов (2).

Hi (имя адресата)

thank you very much for the information and for all your help with the arrangements. (1) Great job! (2)

Do you by any chance know if the students need to bring their bed linen with them? In the information quoted by Lisa it says they do, but I hoped the bed linen could be paid for and provided at Thornbank as it used to be done before. I noticed that the cost of their rooms was originally given at 1192 per week, but the final figure has come out at $£ 205,72$ ( $\$ 411.43$ each per 2 weeks) - could it be that the cost of the bed linen is already included in this price?

With all the best wishes,

(имя адресанта)

Обращение к благодарности на этапе, когда коммуникативная цель еще не была достигнута адресантом и положительный исход только ожидается им, была отмечена нами в эпизоде коммуникации, входящем в цепочку объемом 3 электронных письма, в котором сотрудник британского университета обра- щается к коллеге с просьбой помочь связаться со старой знакомой (1). Включая в речевой акт благодарности объект-стимул «for anything», носитель английского языка имплицитно указывает, что со стороны собеседника он ожидает кооперативного поведения (2):

Dear (имя адресата),

Thank you very much for all this information. I look forward to it.

I wonder whether I could ask for your help with something personal. While I was searching for the materials, I came across a letter from an old friend, (имя, фамилия 1). It had her telephone number and address, but the number was an old 6-figure one, so it didn't work. Might it be possible to contact (имя, фамилия 2) and let (имя 1) know that I'll be in the city? (1) It would be lovely to see her again.

Thanks very much for anvthing you can do. (2)

All best

(имя адресанта)

Использование стратегии благодарения участниками деловой компьютерно-опосредованной переписки было отмечено нами также в дискурсивном событии информирования. Приводимое ниже письмо входит в цепочку объемом 12 эпизодов общения, обмен которыми происходит между преподавателем британского университета, приезжающего с рабочим визитом в российский вуз, и сотрудником международного отдела, ответственного за подготовку программы его пребывания. Получив от организатора информацию, необходимую для оформления визы, носитель английского языка в ответ уведомляет собеседника о том, какие шаги по подготовке приезда в Россию уже были предприняты им и сопровождающим его лицом. Носитель английского языка подчеркивает свою признательность за проделанную коллегой работу как во вступлении (1), так и в блоке прощания (2), что позволяет говорить об искренности выражаемых им эмоций: 


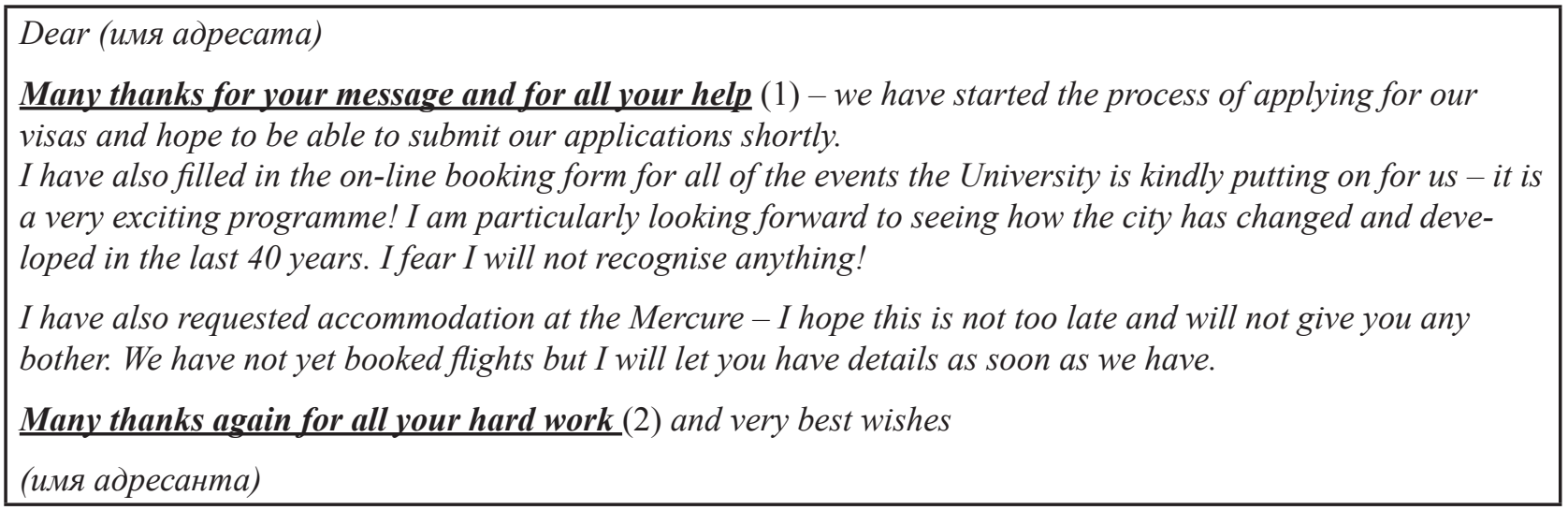

\section{Фатическое благодарение}

Наконец, отметим использование в рамках деловой электронной переписки благодарности фатического типа, являющегося конвенциональным способом установления и размыкания контакта. Подобный тип благодарности представляет большой интерес для исследователей в связи со значимостью ее в британской культуре и частом пренебрежении или осечке в использовании со стороны неносителей языка [19]. Несмотря на то, что ритуальная благодарность рассматривается учеными как «the most formulaic and least heartfelt of expressive illocutionary acts» [20, p. 285; цит. по 21, p. 8], отсутствие ее на определенном этапе интеракции может привести к тому, что общение будет считываться как неадекватное, не удовлетворяющее ожиданиям и не позволяющее адресату правильно исчислить дискурсивные намерения адресанта [22, с. 164].
В зависимости от того, является ли электронное письмо инициативным или реактивным, благодарность будет использоваться и в блоке вступления и прощания, или только в блоке прощания.

В качестве примера использования благодарности рассматриваемого типа в блоке прощания приведем инициативное письмо из ветки объемом 12 эпизодов, входящее в ДС просьбы. Интерактанты - носитель английского языка, приглашенный для участия в академических мероприятиях в российский вуз, и сотрудник данного университета. Обращаясь к представителю организующей стороны с просьбой помочь в выборе визы (1), британский гость прощается через конвенциональную формулу «thanks» (2). Полагаем, что участник общения отдает предпочтение фатическому типу благодарности в силу того, что услуга оценивается им как незначительная:

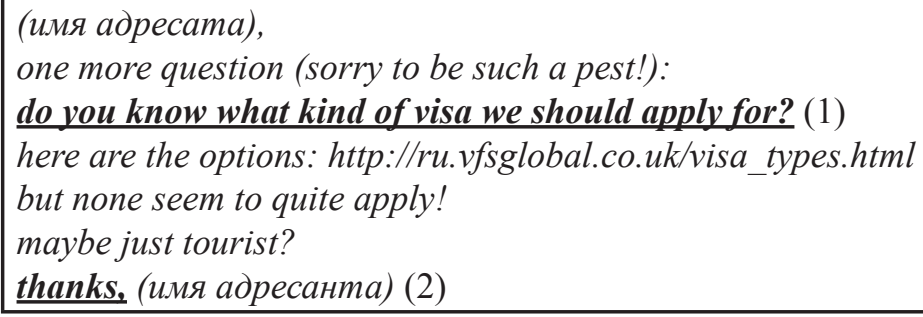

В эпизоде, приведенном ниже (интерактивная цепочка общим объемом 8 писем), носитель английского языка использует благодарность в блоке вступления (1), индикатируя получение корреспонденции, и в блоке прощания (2). Несмотря на использование интенсификатора «many», данный речевой акт благодарности не будет относиться нами к эмфатическому типу в связи с тем, что просьба не расценивается как существенная, и использование более относится к индивидуальным особенностям стиля носителя языка:

Dear (имя адресата),

Many thanks for your email. (1) Just to let you know that we already have our Russian visas so I do not think that we need an invitation. It would be good if you could confirm.

Manv thanks. (2)

Best regards

(имя фамилия адресанта) 
В доказательство того, что данный речевой акт замещает прощание, следует заметить, что очень часто носители языка совмещают ритуальную благодарность и непосредственно формулу прощания, например: «With thanks and regards» или «With thanks and warm regards».

Использование носителями английского языка благодарности одновременно для подтверждения получения ими от собеседника электронного письма и при размыкании контакта было отмечено нами в дискурсивном событии информирования. В качестве примера приведем электронное письмо, относимое нами к ДС информирования типа «Уведомление об отсутствии на рабочем месте». Электронные сообщения подобного рода сообщают адресанту о том, что у собеседника нет возможности отреагировать оперативно на полученное письмо, позволяя таким об- разом держать канал коммуникации в рабочем состоянии. В связи с тем, что получатель не может предугадать, кто именно обратится к нему посредством электронной почты, у сообщений данного типа, как правило, отсутствует приветствие, а речевой акт благодарности выполняет две функции - комплементарной концовки и прощания.

В эпизоде коммуникации, приведенном ниже, носитель английского языка объясняет отсутствие с ее стороны реакции на период новогодних каникул (4) и оставляет контакты коллег, с которыми можно связаться по срочным вопросам на протяжении некоторого времени (3). Следуя конвенциям электронного делового общения, представитель британской лингвокультуры входит и выходит из контакта посредством речевого акта благодарности:

Thank you for your email. (1) I am now away from the University until Thursday 4 January 2018 and so please expect a delay in my response. (4)

On 21 December, if your query is urgent, please contact [имя фамилия] on ... @bham.ac.uk. (3)

On 21 and 22 December, if your query relates to HR, please contact [имя фамилия] оп ... @bham.ac.uk. (3)

The University closes for Christmas/New Year on Friday 22 December and reopens on Thursday 4 January 2018. (4)

Many thanks (2)

Best

(имя адресанта)

Анализ материалов корпуса показывает, что для инофонов крайне нехарактерным является использование благодарности в части прощания. Там, где благодарность включается в письмо, не наблюдается вариативности и, как правило, неносители английского языка ограничиваются «Thank you in advance». В свою очередь, для англичан характерно большое разнообразие формульных фраз благодарения, что подчеркивает дискурсивную значимость фатического речевого акта в лингвокультуре: «Thanks», «With thanks», «many thanks», «Very many thanks», «Many thanks in advance», "Thank you for your patience».

\section{Заключение}

Подводя итог всему вышесказанному, отметим, что рассмотрение цепочек электронного взаимодействия как дискурсивных событий, состоящих из ряда связанных коммуникативных шагов (осуществляе- мых посредством писем), где каждый последующий обусловлен реализацией или неисполнением предыдущего и опирается на него, дает возможность выявить способы поддержания гармоничных и бесконфликтных взаимоотношений на протяжении долгого времени и в рамках многочисленных эпизодов-интеракций. Дискурсивный подход к рассмотрению компьютерно-опосредованной деловой переписки позволяет определить механизмы взаимодействия, вырабатываемые участниками по ходу электронного общения, которые в дальнейшем войдут в их репертуар конвенциональных способов реализации преследуемых в рамках определенного дискурсивного события целей.

\section{ЛИТЕРАТУРА}

1. Murphy M., Matas C. Politeness in Intercultural E-Mail Communication // Handbook of Research on E-Learning Methodologies for Language Acquisition / 
R. Marriott, P. Torres. Information Science Reference, 2008. Pp. 253-270.

2. Li L. Email : a challenge to standard English?// English Today. 2000. No. 16 (4). Pp. 23-29.

3. Воробьева A. E. Структурно-функциональные характеристики текстов электронной деловой корреспонденции (на материале английского и немецкого языков) : автореф. дис. ... канд. филол. наук. Белгород, 2012. $19 \mathrm{c}$.

4. Koriche $H$. The emergence of a new discourse for business communication, 'a case study of e-mails in shipping company' // Procedia - Social and Behavioral Sciences. 2006. No. 199. Pp. 539-547.

5. Garrote P. La cortesía verbal en la interacción asincrónica académica: análisis contrastivo en inglés, español e italiano // Estudios de Lingüística Aplicada. 2014. No. 60. Pp. 117-139.

6. Aston G. Say 'Thank You': Some Pragmatic Constraints in Conversational Closings // Applied Linguistics. 1995. Vol. 16, No. 1. Pp. 57-86.

7. Бердникова А. Г. Речевой жанр благодарности : когнитивный и семантико-прагматический аспекты : автореф. дис. ... канд. филол. наук. Новосибирск, 2005. $24 \mathrm{c}$.

8. Locher M., Watts R. Politeness theory and relational work // Journal of Politeness Research. 2005. No. 1. Pp. 9-33.

9. Серль Дж. Р. Классификация иллокутивных актов // Новое в зарубежной лингвистике. М. : Прогресс, 1988. C. 170-194.

10. Searle J. R. Speech Acts : An Essay in the Philosophy of Language. Cambridge University Press, 1969. 203 p.

11. Leech $G$. The pragmatics of politeness. Oxford University Press, 2014. 350 p.

12. Leech $G$. Principles of pragmatics. Longman Group Limited, 1983. 250 p.

13. Coulmas F. Poison to Your Soul. Thanks and Apologies Contrastively Viewed // Conversational Routine / F. Coulmas (ed.). 1981. Vol. 2. Pp. 69-93.

14. Lakoff $R$. The logic of politeness, or, minding your p's and q's // Ninth Regional Meeting of the Chicago Linguistic Society, 1973. Pp. 292-305.

15. Цурикова Л. В. Дискурсивное событие выражение благодарности в английском и русском языках // Kalbu Studios. 2008. № 13. C. 60-70.

16. Kalaja P., Leppanen $S$. Transaction and interaction in writing: the case of electronic mail // Communication and discourse across cultures and languages. 1991. No. 49. Pp. 266-273.

17. Brown P., Levinson S. C. Politeness: some universals in language usage. Cambridge University Press, 1987. $345 \mathrm{p}$.

18. Цурикова Л. В. Дискурсивные стратегии как объект когнитивно-прагматического анализа коммуникативной деятельности // Вопросы когнитивной лингвистики. 2007. № 4 (013). С. 98-108.
19. Schauer G. A., Adolphs S. Expressions of gratitude in corpus and DCT data: Vocabulary, formulaic sequences, and pedagogy // System. 2006. No. 34. Pp. 119-134.

20. Norrick N. R. Expressive illocutionary acts // Journal of Pragmatics. 1978. No. 2 (3). Pp. 277-291.

21. Kanouta $C$. The Functional Exponents of Expressing Thanks in English : A Mixed Methods Case Study of English Language Didactic Materials in the Greek State Education System. University of Kent, 2015.85 p.

22. Цурикова Л. В. Проблема естественности дискурса в межкультурной коммуникации. Воронеж, 2002. $256 \mathrm{c}$.

\section{REFERENCES}

1. Murphy M., Matas C. Politeness in Intercultural E-Mail Communication. In Handbook of Research on E-Learning Methodologies for Language Acquisition. Ed. by Marriott R., Torres P. Information Science Reference, 2008. Pp. 253-270.

2. Li L. Email: a challenge to standard English? In English Today. 2000. No. 16 (4). Pp. 23-29.

3. Vorob'eva A. E. Strukturno-funktsional'nye kharakteristiki tekstov ehlektronnoj delovoj korrespondentsii (na materiale anglijskogo i nemetskogo yazykov) [Functional and structural characteristics of English and German business letters]: PhD Abstract. Belgorod, 2012. 19 p.

4. Koriche $\mathrm{H}$. The emergence of a new discourse for business communication, 'a case study of e-mails in shipping company'. In Procedia - Social and Behavioral Sciences. 2006. No. 199. Pp. 539-547.

5. Garrote P. La cortesía verbal en la interacción asincrónica académica: análisis contrastivo en inglés, español e italiano. In Estudios de Lingüistica Aplicada. 2014. No. 60. Pp. 117-139.

6. Aston G. Say 'Thank You': Some Pragmatic Constraints in Conversational Closings. In Applied Linguistics. 1995. Vol. 16, No. 1. Pp. 57-86.

7. Berdnikova A. G. Rechevoj zhanr blagodarnosti: kognitivnyj i semantiko-pragmaticheskij aspect [The speech genre of thanking from the cognitive, semantic and pragmatic perspectives]: Dissertation Abstract. Novosibirsk, 2005. 24 p.

8. Locher M., Watts R. Politeness theory and relational work. In Journal of Politeness Research. 2005. No. 1. Pp. 9-33.

9. Searle J. Klassifikatsiya illokutivnykh aktov [A Classification of Illocutionary Acts]. In Novoe v zarubezhnoj lingvistike. Moscow: Progress, 1988. Pp. 170-194.

10. Searle J. R. Speech Acts: An Essay in the Philosophy of Language. Cambridge: Cambridge University Press, 1969. 203 p.

11. Leech G. The pragmatics of politeness. Oxford University Press, 2014. 350 p.

12. Leech G. Principles of pragmatics. Longman Group Limited, 1983. 250 p.

13. Coulmas F. Poison to Your Soul. Thanks and Apologies Contrastively Viewed. In Conversational Routine. Ed. by F. Coulmas. 1981. Vol. 2. Pp. 69-93. 
14. Lakoff R. The logic of politeness, or, minding your p's and q's. In Ninth Regional Meeting of the Chicago Linguistic Society, 1973. Pp. 292-305.

15. Tsurikova L. V. Diskursivnoe sobytie vyrazhenie blagodarnosti v anglijskom i russkom jazykakh [The speech event of thanking in English and Russian]. In Kalbu Studios. 2008. No. 13. Pp. 60-70.

16. Kalaja P., Leppanen S. Transaction and interaction in writing: the case of electronic mail. In Communication and discourse across cultures and languages. 1991. No. 49. Pp. 266-273.

17. Brown P., Levinson S. C. Politeness: some universals in language usage. Cambridge University Press, 1987. $345 \mathrm{p}$.

18. Tsurikova L. V. Diskursivnye strategii kak ob"ekt kognitivno-pragmaticheskogo analiza kommunikativnoj

Воронежский государственный университет

Завьялова Л. А., аспирант кафедры английской филологии

E-mail: zgiglio215@gmail.com

Поступила в редакичию 26 апреля 2020 г.

Принята к публикаџии 15 июня 2020 г.

\section{Для цитирования:}

Завьялова Л. А. Выражение благодарности в деловом дискурсе (на примере англоязычных электронных писем) // Вестник Воронежского государственного университета. Серия: Лингвистика и межкультурная коммуникация. 2020. № 3. C. 79-88. DOI: https://doi. org/10.17308/lic.2020.3/2936 deyatel'nosti [Discursive strategies as the object of cognitive-pragmatic analysis of communication]. In Voprosy kognitivnoj lingvistiki. 2007. No. 4 (013). Pp. 98-108.

19. Schauer G. A., Adolphs S. Expressions of gratitude in corpus and DCT data: Vocabulary, formulaic sequences, and pedagogy. In System. 2006. No. 34. Pp. 119-134.

20. Norrick N. R. Expressive illocutionary acts. In Journal of Pragmatics. 1978. No. 2(3). Pp. 277-291.

21. Kanouta C. The Functional Exponents of Expressing Thanks in English: A Mixed Methods Case Study of English Language Didactic Materials in the Greek State Education System: Master's Dissertation. University of Kent, 2015. $85 \mathrm{p}$.

22. Tsurikova L. V. Problema estestvennosti diskursa v mezhkul'turnoj kommunikatsii [The problem of natural discourse in the context of intercultural communication]. Voronezh, 2002. 256 p.

Voronezh State University

Zavialova L. A., Post-graduate Student of the English Philology Department

E-mail: zgiglio215@gmail.com

Received: 26 April 2020

Accepted: 15 June 2020

\section{For citation:}

Zavialova L. A. Expressing gratitude in the email-based business communication. Proceedings of Voronezh State University. Series: Linguistics and Intercultural Communication. 2020. No.3. Pp. 79-88. DOI: https://doi.org/10.17308/ lic. $2020.3 / 2936$ 